\title{
Cardiac Troponins: Contemporary Biological Data and New Methods of Determination
}

\author{
Aleksey Chaulin (1D) 1,2 \\ 'Department of Cardiology and \\ Cardiovascular Surgery, Samara State \\ Medical University, Samara, 443099 , \\ Russia; ${ }^{2}$ Department of Histology and \\ Embryology, Samara State Medical \\ University, Samara, 443099, Russia
}

\begin{abstract}
Laboratory diagnosis plays one of the key roles in the diagnosis of many diseases, including cardiovascular diseases (CVD). The methods underlying the in vitro study of many CVD biomarkers, including cardiac troponins (cTnI and $\mathrm{cTnT}$ ), are imperfect and are continually being improved to enhance their analytical performance, with sensitivity and specificity being the most important. Recently developed improved cTnI and cTnT detection methods, referred to as highly sensitive methods (hs-cTnI, hs-cTnT), have changed many of our ideas about the biology of cardiac troponins and opened up a number of additional diagnostic capabilities for practical healthcare. This article systematizes some relevant data on the biology of cardiac troponins as well as on methods for determining cTnI and cTnT with an analysis of the diagnostic value of their analytical characteristics (limit of blank, limit of detection, 99th percentile, coefficient of variation, and others). Data on extracardiac expression of $\mathrm{cTnI}$ and $\mathrm{cTnT}$, mechanisms of formation and potential clinical significance of gender, age, and circadian characteristics of hs-cTnI and hs-cTnT content in serum are discussed. Considerable attention is paid to the discussion of new diagnostic capabilities of hs-cTnI, hs-cTnT, including consideration of promising possibilities for their study in biological fluids that can be obtained by non-invasive methods. Also, some possibilities of using hs-cTnI and hs-cTnT as prognostic laboratory biomarkers in healthy people (for example, to assess the risk of developing CVD) and in patients suffering from a number of pathological conditions that cause damage to cardiomyocytes are examined, and the potential mechanisms underlying the increase in hs-cTnI and hs-cTnT are discussed.
\end{abstract}

Keywords: laboratory diagnostics, cardiovascular diseases, acute myocardial infarction, biomarkers, cardiac troponins, cTnI, cTnT highly sensitive methods, hs-cTnI, hs-cTnT, analytical characteristics, 99th percentile, limit of detection, coefficient of variation

\section{Introduction}

\section{Important Aspects of the Clinical Biochemistry of Cardiac-Specific Troponins}

There are three different troponin proteins ( $\mathrm{cTnI}, \mathrm{cTnT}$ and $\mathrm{cTnC}$ ) in the troponin complex localized in human cardiac striated muscle. Their functional role is to regulate the contraction and relaxation of myocardial tissue. ${ }^{1,2}$ The structure (sequence of amino acids in peptide chains) of cTnI, cTnT and cTnC is important for the functional state of the cardiac muscle. Numerous genetic studies revealed a large number of mutations in genes encoding troponin proteins (for example, by the type of substitution or deletion of one or several nucleotides), which led to the replacement of the corresponding amino acids and disruption of the regulatory function of troponins, phenotypically manifested in
Correspondence: Aleksey Chaulin Department of Cardiology and Cardiovascular Surgery, Samara State Medical University, 89 Chapaevskaya Street, Samara Region, Samara, 443099 Russia

Tel +7 (927) 7702587

Email alekseymichailovich22976@gmail. com 
the form of various contractile dysfunctions and cardiomyopathies. ${ }^{3-8}$ The etiopathogenesis and clinical manifestations of such disorders are described in sufficient detail in several review papers. ${ }^{6-8}$

The amino acid composition of the two proteins included in the troponin complex (cTnI and cTnT) of the cardiac muscle differs from the amino acid composition of these proteins localized in the troponin complex of skeletal muscle, while the amino acid composition of $\mathrm{cTnC}$ and skeletal troponin $\mathrm{C}$ are completely identical. ${ }^{1,2,9}$

The main site of localization of cardiac-specific troponin proteins (cTnI, cTnT) is the myocardium, which allows their use as specific biomarkers for identification of cardiac muscle alteration. ${ }^{1,9,10}$ However, there are a number of studies that refute the absolute cardiospecificity of cTnI and cTnT. According to some reports, cTnI and cTnT expression has been found in skeletal muscle tissue in chronic renal failure (CRF), ${ }^{11-13}$ as well as in a number of hereditary and acquired myopathies. ${ }^{11,14-16} \mathrm{In}$ addition, there are works reporting on the $\mathrm{TnI}$ and $\mathrm{cTnT}$ expression in the tunica media of the vena cava and pulmonary veins. ${ }^{17,18}$ However, the data on the existence of extracardiac expressions for cTnI and cTnT are contradictory. ${ }^{19,20}$ For example, in a recent study published in the Journal of the American College of Cardiology, researchers found no trace of cTnI and cTnT expression in the skeletal muscles of patients with congenital and acquired skeletal myopathies and no obvious signs of cardiovascular disease (CVD). ${ }^{20}$ At the same time, cTnI and cTnT levels were increased in \% of the examined patients, respectively. According to the authors, the most probable reason for the increase in cTnI and cTnT, in this case, was cross-reactions of diagnostic anticTnI and anti-cTnT antibodies with skeletal troponins released from damaged muscle fibers. ${ }^{20}$ Another possible cause of cTnI and cTnT increase in hereditary myopathies may be mutations of these proteins, affecting those parts of the molecule against which the diagnostic antibodies are directed. This will lead to a change in the antigen-antibody interaction, which is a fundamentally important stage in all immunochemical detection methods for the examined analytes.

According to biochemical studies of myocardial samples, the total content of cTnI and cTnT in human myocardium is about $4.0-6.0 \mathrm{mg}$ and $10.0-11.0 \mathrm{mg}$ per $1 \mathrm{~g}$ wet weight of tissue, respectively. ${ }^{21-23}$ The largest part of troponins (about 95\%) of this total amount is located in the troponin complex, and is responsible for myocardial contractility. And a much smaller part of troponins (about $5 \%$ ) is freely localized in the cytoplasm of cardiomyocytes without taking part in the regulation of contraction and relaxation in the myocardium. ${ }^{2,8,10}$ The functional significance of this fraction has not been established; however, in terms of clinical biochemistry and laboratory diagnosis, it plays an important role in the early identification of many pathological conditions accompanied by cardiac muscle damage, including acute myocardial infarction (AMI). ${ }^{10,24-26}$ This is due to the fact that these cytoplasmic proteins are released into the extracellular space much earlier than from the troponin complex, whose degradation rate takes longer. ${ }^{25,26}$ The mechanisms of cTnI and cTnT release in the early stages of many pathological conditions may be associated with an increase in cell membrane permeability and/or intracellular cleavage of $\mathrm{cTnI}$ and cTnT molecules into smaller fragments that can freely pass through the intact cell membrane. ${ }^{24,27,28}$ Establishing the exact mechanisms of damage and release of cTnI and cTnT will be important for optimizing laboratory diagnosis of many pathological conditions that cause damage to the cardiac muscle.

\section{Cardiac-Specific Troponins (cTnl and cTnT) as Laboratory Biomarkers of Myocardial Injury: Practical Application Possibilities}

Among all currently known laboratory biomarkers of AMI, ${ }^{10,24,29-31}$ cardiac troponins remain the most demanded ones in clinical practice; however, they are not devoid of several disadvantages, among which the following ones are worth mentioning: 1) relatively late time of establishing the fact of cardiomyocyte damage or death, 2) insufficient specificity in relation to ischemic necrosis of cardiomyocytes in AMI, and this is manifested by the fact that at the early stages of examination it is almost impossible to establish the cause and mechanism of cardiac muscle damage, which is key to making a correct diagnosis, 3) lack of standardization of existing methods of determination, which is expressed by the fact that diagnostic tests of different manufacturers, having different analytical characteristics, give different results in samples received from the same patient, and in some cases, in particular during transportation or transfer of patients to another hospital, that does not allow to assess dynamic changes of cTnI and cTnT levels. 
Due to the fact that any myocardial cell damage, even reversible, can be accompanied by an increase in $\mathrm{cTnI}$ and cTnT serum concentrations, these biomarkers cannot be considered specific biomarkers of ischemic myocardial damage characteristic of AMI and when making this diagnosis, should not be relied on laboratory diagnostic data only. ${ }^{27,28,32-35}$ To make a correct diagnosis, in addition to the laboratory diagnostic criteria, clinicians must necessarily consider the clinical picture, electrocardiogram and echocardiogram data; otherwise, the risk of misdiagnosis and incorrect treatment, which can cause harm to the patient, increases significantly. ${ }^{35}$ Thus, $\mathrm{cTnI}$ and $\mathrm{cTnT}$ can be considered as specific biomarkers of any myocardial damage, but cannot be considered specific for any particular type of damage or pathological condition affecting myocardial tissue. As an exception to this rule, a group of causes of falsepositive increases in cTnI and cTnT can be noted, which includes cross-reactions of diagnostic anti-cTnI and anticTnT antibodies with skeletal troponins, the influence of heterophilic antibodies, alkaline phosphatase, biotin, hemolysis, ictericity and lipemia. ${ }^{33,36}$ In general, the main reasons for the increase in $\mathrm{cTnI}$ and $\mathrm{cTnT}$, which are not directly related to AMI, can be divided into three groups (Figure 1).

In some cases, even the combination of additional electrocardiogram data indicating ischemia and the rise in cTnI and cTnT levels characteristic of AMI cannot guarantee a correct diagnosis. Some of the results of clinical studies and descriptions of clinical cases are striking examples of the above. ${ }^{35,37-40}$ Since many patients with atrial fibrillation and supraventricular tachycardia (SVT) develop symptoms of chest pain, and the electrocardiographic picture and dynamics of the increase in the concentration of cTnI and cTnT are also similar to the dynamics of cardiac troponin levels in AMI, such patients are often mistakenly diagnosed with AMI and prescribed inappropriate treatment with antiplatelet and thrombolytic drugs. Xue et al describe 2 cases in which patients with SVT were misdiagnosed with AMI. Both patients had elevated cTnI on admission with complaints of chest pain (0.09 and 0.16 $\mathrm{ng} / \mathrm{mL}$, respectively, with a norm of 0.08 ). A few hours after hospitalization, there was an even more significant increase in troponin I concentration to 0.52 and 2.28, respectively, which resulted in the patients being wrongly diagnosed with AMI and prescribed corresponding treatment, which nevertheless did not improve the patients' condition. Within several days after hospitalization, the patients underwent coronarography, which did not reveal any signs of coronary artery obstruction. ${ }^{37}$ Thus, in some cases, only coronary angiography allows for differential diagnosis and excludes signs of coronary artery disease in patients with SVT.

In some cases, even the increase in cardiac troponins at physical load can complicate the differential diagnosis and lead to overdiagnosis of AMI. For example, Manjunath described a case of elevated troponin I $(0.123 \mathrm{ng} / \mathrm{mL}$ with a normal value of $<0.055 \mathrm{ng} / \mathrm{mL}$ ) in a young patient admitted to the emergency department with chest discomfort. Based on these data, clinicians suspected AMI. Additionally, unfavorable family history and lipid profile (significant increase of total cholesterol and low-density lipoproteins) were indicative of AMI. At the same time, ECG, Echo-CG and coronarography showed no signs of

Three groups of possible causes of increased cardiac troponin concentrations that are not associated with
acute myocardial infarction

Figure I Main groups of causes of increased $\mathrm{cTnl}$ and $\mathrm{cTnT}$ that are not associated with AMI, according to ${ }^{33,36}$ as amended. 
ischemia. Subsequently, careful history taking revealed that the young man was actively engaged in sports and ran several miles on the eve of admission, preparing for a marathon. ${ }^{38}$ More information on the prevalence, mechanisms, as well as problems and difficulties of differential diagnosis in various pathological conditions, including acute aortic dissection, pulmonary embolism, sepsis, CRF and a number of others is summarized in a review by Long et al. ${ }^{35}$ Misinterpretation of elevated cardiac troponin levels in some conditions may, for example, result in prescription of anticoagulant or antiplatelet therapy in patients with acute aortic dissection and lead to disastrous consequences for such patients. Several studies have also described erroneous diagnoses of AMI due to falsepositive causes of the increase, in particular, under the influence of heterophilic antibodies ${ }^{39}$ and alkaline phosphatase $^{40}$

Besides, in the early stages of patients' admission, elevated levels of cTnI and cTnT do not allow differentiating the types of myocardial damage, in particular, distinguishing reversible damage, in which complex therapeutic measures should not be carried out, from irreversible damage, in which therapy should be started as soon as possible. This is due to the fact that in the early stages of myocardial damage (regardless of whether it is reversible or not), the concentration of troponins is low (the degree of excess relative to the values of the 99th percentile can be up to 5 times) and may be associated with the release of cTnI and cTnT molecules that make up the cytosolic fraction. ${ }^{41}$ The degree of cTnI and cTnT increase during psychoemotional stress is lower than during severe physical activity, such as marathon running, which is caused by less damaging effect on cardiomyocytes. ${ }^{42}$

As to reversible cardiac muscle damage, it can be noted that cardiomyocytes can be damaged in many physiological (physical load, psychoemotional stresses) and initial stages of pathological conditions, such as myocarditis, ${ }^{43,44}$ sepsis, ${ }^{4-47} \mathrm{CRF},{ }^{48-50}$ cardiac rhythm disorders (atrial fibrillation and supraventricular tachycardia), ${ }^{37,51-53}$ chemotherapy treatment of cancer ${ }^{54}$ and some other conditions not associated with AMI provided that the damaging factor is eliminated. ${ }^{27,28,35}$ This circumstance has both a negative value, creating additional difficulties for physicians and complicating the differential diagnosis of AMI from these nosologies, and an important positive value, allowing the use of cTnI and cTnT molecules for diagnostic and prognostic purposes in these conditions.
However, for the time being, the potential for such use of cTnI and cTnT is limited by a number of circumstances, including 1) insufficient knowledge on and understanding of the specific mechanisms of damage and subsequent increase in cTnI and cTnT in these physiological and pathological conditions, 2) little specific or almost similar dynamics (kinetics) of cTnI and cTnT concentration in AMI and a number of non-AIM-related pathological conditions that damage the myocardium.

Analyzing the mechanisms of damage and increase in cTnI and cTnT levels according to the results of clinical and experimental studies leads to a conclusion that they are multiple and complex in nature. For example, in sepsis, alteration of cardiomyocytes is possible due to direct damaging effects of inflammatory mediators and cytokines. ${ }^{45}$ Another mechanism of myocardial damage in sepsis is the imbalance between myocardial oxygen demand and oxygen delivery, which can occur even in absolutely intact coronary arteries and is somewhat similar to the mechanisms of type $2 \mathrm{AMI}^{46}$ As a result, sepsis is often accompanied by severe tachycardia, in which cardiomyocytes need much more oxygen and energy substrates (glucose, free fatty acids, lactate) to generate ATP energy in cardiomyocytes to ensure optimal life; however, the delivery capacity remains the same, which cannot fully meet the increased demand. Under such conditions, it is likely that intracellular acidosis is gradually formed due to transition of myocardium to anaerobic metabolism, which leads to activation of apoptotic enzymes (caspases), causing proteolysis of protein troponin molecules into smaller fragments and their exit from cardiomyocytes and additionally, damage of protein-lipid components of cell membrane is possible, which will increase its throughput in relation to small fragments of cTnI and cTnT. Another mechanism responsible for the growth of cTnI and cTnT may be a decrease in their elimination from the blood due to a sharp drop in blood pressure and renal filtration. This mechanism may be supported by a correlation between troponin levels and the CRF marker (creatinine) in patients with sepsis. ${ }^{4,55}$ As for CRF, the mechanisms for increasing are also multiple and highly debatable According to some data, a decrease in renal filtration may be a responsible mechanism for the increase in troponins, which will lead to the accumulation of cTnI and cTnT molecules in serum. Thus, according to the study, more than half of the examined patients without clear signs of CVD had elevated cTnT concentrations, and patients with lower glomerular filtration rate (GFR) had higher cTnT 
levels than patients with higher GFR. ${ }^{48}$ The results of this study also confirm the dependence of serum levels of cardiac-specific troponins on the functional state of the kidneys, which can be suppressed in sepsis and, by a similar mechanism, lead to an increase in serum levels of $\mathrm{cTnI}$ and $\mathrm{cTnT}$. Another mechanism responsible for the growth of troponins in CRF may be the adverse effect of accumulated toxic metabolic products that have a direct cytotoxic effect on the myocardium. ${ }^{33,49,50}$ In addition, in conditions of chronic renal failure, the volume of circulating blood may increase, leading to a proportional increase in blood pressure and myocardial load. The latter circumstance will trigger a number of intracellular signaling pathways, leading to activation of enzymes (caspases, matrix metalloproteinases, calpain), causing splitting of molecules into small fragments inside the cell and their release outside. ${ }^{26,56}$ Finally, another mechanism underlying the increase in $\mathrm{cTnI}$ and $\mathrm{cTnT}$ may be the activation of the expression of these molecules in skeletal muscle tissues in CRF, which was discovered by Ricchiuti and Apple. ${ }^{11}$

As noted above, under physiological conditions, for example, prolonged exertion, psychoemotional stress or transient episodes of ischemia, cardiomyocytes are damaged, as a rule, insignificantly and the nature of the damage itself is reversible. The serum concentrations of $\mathrm{cTnI}$ and $\mathrm{cTnT}$ are probably formed by only those troponins that are freely located in the cardiomyocyte and the troponin complex is not affected and that is why the degree of $\mathrm{cTnI}$ and $\mathrm{cTnT}$ increase is much less significant than in other pathological processes. The release of cytoplasmic molecules cTnI and cTnT is probably associated with the development of transient ischemia due to the imbalance between oxygen demand and oxygen delivery with increasing demand. The main argument in favor of the fact that damage to cardiomyocytes is reversible is the kinetics of troponin levels: for example, in myocardial infarction, the duration of the circulation of troponin proteins is $1-2$ weeks, while even with excessive physical exertion, it averages 1-2 and no more than 3 days, after which it returns to normal with no consequences. ${ }^{41}$ The second argument in favor of the reversibility of myocardial damage is the data of magnetic resonance imaging (MRI) with gadolinium-based contrasts. This method, in accordance with the modern development of science, is ideal for visualizing inflammation and myocardial fibrosis. R. O'Hanlon et al visualized myocardial tissue of 17 athletes (11 of them had elevated levels of hs-cTnI) by MRI and found no signs of necrosclerotic changes. ${ }^{57}$

\section{Some New Data on Troponin Biochemistry and Diagnostic Capabilities of High-Sensitivity Troponin Assays}

The development and introduction of high-sensitivity troponin (hs-cTnI and hs-cTnT) determination methods in 2007-2010 XXI century has significantly changed many of our ideas about cardiac troponin biochemistry and expanded diagnostic capabilities for the use of these biomarkers in practical medicine. For example, hs-cTnI and hs-cTnT were detected in almost all absolutely healthy patients using these methods of determination, which allows to consider hs-cTnI and hs-cTnT molecules as products of normal myocardial metabolism; ${ }^{58,59}$ however, it is true only if hs-cTnI and hs-cTnT levels do not exceed the 99th percentile, the currently accepted upper reference limit, corresponding to the concentration of cardiac troponin molecules detected in $99 \%$ of truly healthy individuals, with only $1 \%$ of truly healthy individuals having elevated values. Previously, cardiac troponin molecules were considered only as strictly intracellular compounds, the detection of which in blood was considered a key criterion for AMI. ${ }^{60}$

Gender, age and circadian features provide quite remarkable information obtained by highly sensitive methods about the troponin biology. ${ }^{61}$ With regard to gender characteristics, it was found that the level of cardiacspecific troponins in men is higher than in women, which is recommended to be used to determine the values of 99th percentile in modern diagnostic algorithms for the diagnosis of AMI. ${ }^{62-64}$ The higher level of cardiac troponins in men is explained by the fact that they have a larger left ventricular mass than women. ${ }^{63-65}$ Age-related features of troponin levels are that the older patients have higher concentrations than younger ones. It is suggested that this may be related to the comorbidity, which can negatively affect cardiomyocytes. ${ }^{24,34,65,66}$ In accordance with the recently discovered circadian features of hs-cTnI and hs-cTnT levels, it was shown that the values of the latter are slightly higher in the morning hours compared to the evening both in healthy patients ${ }^{67-69}$ and in patients with $\mathrm{CRF}^{70}$ It is noteworthy that circadian fluctuations of hscTnT concentrations are much more pronounced in patients with comorbid pathologies, in particular CRF and diabetes mellitus, than in healthy patients. ${ }^{61}$ According to some reports, circadian rhythms may have a potential impact on the accuracy of early diagnosis of 
AMI and screening for CVD. ${ }^{36}$ For example, hs-cTnI and hs-cTnT levels that naturally change throughout the day can be erroneously interpreted as diagnostically significant abnormalities. In one clinical case described by van der Linden ${ }^{70}$ the diagnostically significant influence of circadian rhythms on the early diagnosis of AMI was demonstrated using diagnostic algorithms developed by the European Society of Cardiology. ${ }^{30,36,71}$

The exact mechanisms for the formation of circadian features in cardiac troponin concentrations have not been established, but it can be assumed that it is associated with circadian features of other human systems that, to varying degrees, adversely affect the cardiovascular system (CVS). Sympathoadrenal, renin-angiotensin-aldosterone, hypothalamic-pituitary-thyroid systems, and hemostasis system components are among such adverse factors affecting the cardiovascular system. The increased activity of these systems in the morning is necessary for a healthy person to maintain the optimal period of wakefulness; however, these systems can have an additional adverse effect on the state of the CVS both in normal and in pathological conditions. ${ }^{36,71}$ For example, according to several studies, the size of the necrosis zone and the levels of cardiomarkers also have similar circadian features, exhibiting maximum values in the morning. ${ }^{72,73}$ It is also quite remarkable that the peak activity of the above systems practically coincides with the peak levels of cardiac troponins in the morning, which is further evidence in favor of the mechanisms of this formation of hs-cTnI and hscTnT circadian rhythms.

The sensitivity of hs-cTnI and hs-cTnT proved to be so high that it allowed to change our understanding of the ways and mechanisms of elimination of cardiac troponin molecules and to open up opportunities for studying hscTnI and hs-cTnT in biological fluids that can be obtained non-invasively, which is important and a promising advantage. For example, in earlier studies, cTnI and cTnT molecules were not detected by standard moderately sensitive methods in urine, which led to the assumption that cTnI and cTnT are too large compounds and cannot be eliminated through the renal filter. ${ }^{74,75}$ However, in a recent study using high-sensitivity immunoassays, hs-TnT was detected in the morning urine of all subjects, and hs-TnT levels were significantly higher in the urine of hypertensive patients than in those with normal blood pressure. ${ }^{76}$ Thus, it can be concluded that the concentrations of troponins in urine are rather small and cannot be detected by moderately sensitive tests, but with the use of highly sensitive methods, this may in the future become a new valuable diagnostic approach. In addition to urine, oral fluid is also planned to be used for non-invasive diagnostics. ${ }^{77-79}$ The following can be noted as the advantages of non-invasive determination: 1) obtaining the biomaterial from patients is atraumatic and painless, and does not lead to anemisation of patients during repeated sampling of biomaterial for research, 2) the risk of bloodborne diseases (HIV, viral hepatitis, etc.) is reduced, 3) no trained medical personnel are required to obtain biological samples and the biomaterial can be sampled by the patient himself at home. And with the development of portable dry chemistry tests, the idea of which was proposed by Potkonjak et al, ${ }^{80}$ it is now possible to conduct such tests outside the laboratory (at home, in the emergency medical care, and at the patient's bedside).

\section{A Brief Historical Background on the Development of Troponin Immunoassays}

A large number of methods based on different principles of determination of analytes have been developed to date for the quantitative and qualitative determination of cTnI and cTnT. Immunochemical methods (enzyme immunoassay, radioimmune assay, immunofluorescence assay, and immunochemiluminescence assay) are among the most frequently used and reliable methods in clinical practice. Several successive stages can be distinguished on the basis of their analytical determination: immunological, chemical, and the stage of detection. The first (immunological) phase is identical for all immunochemical methods and consists in a specific interaction of diagnostic anti-cTnI or anti-cTnT antibodies with the antigen, which in this case is the molecule sought - cTnI or cTnT, respectively. The second stage of immunochemical methods is different. At this stage, an additional immunological reaction occurs with antibodies directed against the first diagnostic anticTnI or anti-cTnT antibodies and the formation of a sandwich-type complex, or a chemical (enzymatic) reaction takes place. In the third stage, the received signal is registered. Depending on the antibody label used, the methods for detecting the generated signal also differ: in the case of enzyme-linked immunosorbent assay, the color intensity is assessed using a photometer/spectrophotometer; in the case of radioimmunoassay, where radioisotopes (radionuclides) are used as a label, it is evaluated with a radiometer (radio spectrometer), and in the case of using fluorophores, the signal is recorded on 
a fluorometer. The strength of the generated signal is directly proportional to the number of analyte molecules, which allows accurate quantification of cTnI and cTnT concentrations by the calibration curve. The result of a laboratory study of troponin levels is expressed in several different units, among which the most commonly used are $n g / m L, n g / L, \mu g / L$ (quantitative methods of determination), or a visual assessment of the number of stripes formed and/or the degree of their staining is carried out, which is typical for qualitative and semi-quantitative methods for determining cTnI and cTnT (diagnostic test strips), often used at the patient's bedside or during transport in the ambulance to obtain preliminary results.

Due to the development of protein analysis methods, the cardiospecificity of cTnI and cTnT molecules was proved, and the main efforts of researchers were aimed at creating methods for the identification of these compounds, since the enzymes (aspartate aminotransferase, lactate dehydrogenase, creatine phosphokinase) used then were of low efficiency with regard to AMI diagnosis. ${ }^{81,82}$ Some of the earliest immunoassay methods for cTnI and cTnT determination appeared almost 35 years ago and gradually improved their analytical characteristics and, as a consequence, their diagnostic capabilities as they approached the present time.

The very first method for determining cTnI in serum, based on radioimmunoassay, was developed in 1987. It had a detection limit (minimum detectable concentration) of about $10 \mu \mathrm{g} / \mathrm{L}(10,000 \mathrm{ng} / \mathrm{L})$ and the analysis time was extremely slow - about 1-2 days. Due to such a low sensitivity and duration of the study, the time for detecting diagnostically significant concentrations of troponin in the blood was late and this method could only detect extensive myocardial infarction; therefore, cTnI was significantly inferior to the creatine kinase-MB (CK-MB) enzyme, which was actively used at that time and considered the "gold standard" for diagnosis of AMI. ${ }^{83}$ A few years later, Katus et al presented the first fully automated enzymelinked immunosorbent assay (ELISA) for cTnT determination, which had a detection limit of about $100 \mathrm{ng} / \mathrm{L}$ and took only 90 minutes to run, which was a real breakthrough at its time. According to the results of clinical studies, peak cTnT concentrations correlated with peak CK-MB levels in patients with AMI. This immunoassay, also referred to as the "first generation assay", was still somewhat inferior to some standard biomarkers, including the CK-MB, used at that time for AMI diagnosis. ${ }^{84,85}$ However, this method had a significant disadvantage consisting in cross-reactivity of diagnostic antibodies with troponin isoforms characteristic of skeletal muscles and high percentage of positive results in skeletal muscle diseases (myopathies) and heavy physical exertion (during marathon running); another disadvantage was still low sensitivity. ${ }^{10,22,85}$ The second-generation methods were characterized by higher specificity and sensitivity, which was expressed in the reduction of cross-reactivity with skeletal troponins and possibilities of earlier diagnosis of AMI (on average, 6-12 $\mathrm{h}$ after its development), due to which cTnT has finally surpassed all other biomarkers available at that time, including CK-MB. In 2000, in a joint document of European and American Cardiology Societies, experts recommended to use cTnT for AMI diagnosis in routine clinical practice. $^{82}$ Subsequent improvement of cTnT determination methods resulting in the creation of "third" and "fourth generation" immunoassays has almost completely eliminated cross-reactivity of diagnostic antibodies with skeletal troponins, as well as improved some analytical characteristics, including the detection limit (minimum detectable concentration). In addition, the assay time was almost halved and the advantage in the diagnosis of AMI was finally passed from CKMB to $\mathrm{cTnT}^{31}$ Low sensitivity and a prolonged average time required for accurate laboratory diagnosis of AMI (detection of diagnostically significant levels of cardiac troponins in the blood) were still considered a disadvantage of such moderately sensitive methods; therefore, work on improving the methods, in particular, increasing their sensitivity, continued. On average, it took about 6-12 hours from the moment of the development of the clinical picture of AMI for the final laboratory confirmation of the diagnosis. ${ }^{86}$ The first reports on highsensitivity assays (hs-cTnT from Roche Diagnostics) referred to as "fifth generation" immunoassays, appeared in 2007-2010. They had a detection limit of 1-10 ng/L, which was about tens and hundreds of times higher than the detection limits of moderately sensitive third- and fourth-generation methods and thousands of times higher than prototypes of 30 years ago, and the time required for testing was only $20-30 \mathrm{~min}^{.87-89}$

Immunoassays for cTnI detection have undergone almost a similar evolution since the first prototype was developed by Cummins in 1987. A few years later, in 1992, an enzyme-linked immunosorbent assay was developed, the main components of which were enzyme-labeled monoclonal antibodies directed against antigenic determinants (epitopes) of the cTnI molecule. The detection limit 
(minimum detectable concentration) of this method of determination was $1900 \mathrm{ng} / \mathrm{L}$, and the time to perform a laboratory test was about 3.5 hours. ${ }^{90,91}$ In contrast to cTnT determination methods existing at that time, this assay was highly specific for detection of myocardial damage, and false-positive results in skeletal muscle diseases (myopathies), CRF and heavy physical exertion (marathon running) were practically not observed, while for cTnT methods this was a big problem. It is very likely that the emergence of dubious hypotheses about the presence of cTnT expression outside the myocardium, in particular in skeletal muscles, ${ }^{1-14}$ is partly due to the use of such low-specific immunoassays. Over the past 25 years, several dozen immunoassays with various combinations of diagnostic antibodies directed against different antigenic determinants of the cTnI molecule have been developed. To date, there are more than 30 commercially available tests for the determination of cTnI. The available methods range from older, less sensitive models to modern, high- and ultrasensitive immunoassay methods. Due to the heterogeneity of cTnI assay methods, quantitative results obtained for the same patient using different methods and on different analyzers (devices) do not coincide. Standardization of cTnI determination methods based on different platforms remains a challenge and is one of the main problems. ${ }^{91}$ Thus, if it becomes necessary to transport a patient to another hospital where a different method of determination is used, the results of cTnI concentration may not correlate, so they cannot be evaluated over time and require additional studies accompanied by economic and time costs.

Among the most well-known and frequently used highsensitivity immunoassays approved by the International Federation of Clinical Chemistry (IFCC) are the highsensitivity tests of the following companies: Abbott (USA), Beckman Coulter (USA), bioMerieux (France), LSI Medience Corporation (Japan), Roche Diagnostics (Switzerland), Ortho-Clinical Diagnostics (USA), Siemens Healthineers (Germany), Singulex (USA). ${ }^{92,93}$ Among them, only Roche produces immunochemical test kits for hs-TnT determination, while all others produce kits for hs-TnI. Thus, the most important advantage of using hs-TnT is the standardization of research results. A major disadvantage of hs-TnI immunochemical test kits is the lack of standardization, which is manifested by a strong difference in the results of test of the blood serum of the same patient obtained with commercial kits, and certain concentrations may differ by more than 5-10 times. ${ }^{92}$ This is primarily due to the fact that different antihs-TnI antibodies directed to different antigenic determinants of the cTnI molecule are used in different kits. In accordance with recent research results, it has been established that cTnI and cTnT fragments that have different stability ${ }^{94,95}$ differ in resistance to various proteolytic enzymes $^{96,97}$ and in elimination abilities, ${ }^{48,74,76}$ circulate in the blood to a greater extent in AMI. For example, when using antibodies directed against unstable epitopes or fragments of cTnI and cTnT, the results of the test may be underestimated in comparison with those obtained using test kits with anti-cTnI and anti-cTnT antibodies against more stable fragments or areas of cardiac troponin molecule. In addition, some epitopes of troponin molecules are targets of autoantibodies and heterophilic antibodies, which can lead to a large number of false positive or false negative results when testing serum by a particular test. $^{98-100}$ Further studies are needed to clarify the mechanisms of the influence of various proteolytic enzymes that cause the cleavage of cTnI and cTnT molecules ${ }^{94-97}$ and the mechanisms of interference of heterophilic antibodies, which will help to develop measures eliminating this effect and will contribute to improving the quality and standardization of immunochemical methods of determination.

\section{High-Sensitivity Troponin Assays: Prevalence, Analytical Characteristics, Criteria, Classification}

By now, many health care institutions have switched to IFCC-approved high-sensitivity cTnI and cTnT assays. Anand et al recently conducted an assessment of the global prevalence of use of high-sensitivity tests and implementation of the key recommendations of the Universal Definition of Myocardial Infarction (2018) for the use of hs-cTnI and hs-cTnT. The researchers surveyed practitioners from 1902 medical centers in 23 countries on 5 continents. According to the results of the study, it turned out that cardiac troponins are used as the main diagnostic marker of AMI in $96 \%$ of institutions. While, only $41 \%$ of medical centers used high-sensitivity assays, with a wide range from $7 \%$ in North America to $60 \%$ in Europe. Institutions practicing hs-cTnI and hs-cTnT, usually applied the strategy of serial measurements of the hscTnI and hs-cTnT concentrations in the early hours of the patient's admission ( $0-3$ hours) and used manufacturer's recommended values of 99th percentile upper 
reference limit; however, only $18 \%$ of doctors took into account the gender characteristics of 99th percentile. ${ }^{93}$

For the currently used methods for the determination of cTnI and cTnT, a number of basic analytical characteristics are assessed that determine the diagnostic value of cardiac troponins: 1) limit of blank (LoB) - the maximum concentration of an analyte that can be detected in a sample that does not contain the analyte under study, 2) limit of detection (LoD) or minimum detectable concentration (MDC) - the minimum concentration of an analyte that can be detected using the tests in use, 3) the limit of quantitation (LoQ) or functional sensitivity - the lowest concentration of an analyte in a test sample that can be determined with acceptable repeatability and accuracy, 4) 99-percentile (general), 5) 99-percentile (taking into account gender characteristics), 6) percentage of measurable values in healthy individuals - the number of people (in \%) with hs-cTnI and/or hs-cTnT concentration in blood above the LoD, but not exceeding the values of the 99th percentile, 7) coefficient of variation (CV\%), 8) 99th percentile/LoD ratio. ${ }^{63,101-103}$

Currently, there is some confusion regarding the designation of high-sensitivity immunoassays, and manufacturers and/or researchers often wrongly designate some immunoassays as highly sensitive, which may lead to incorrect interpretation of the test outcomes. In this regard, many practitioners and researchers have a question: which immunoassay should be considered highly sensitive? The IFCC Task Force on Clinical Applications of Cardiac BioMarkers (TF-CB IFCC) proposed to designate as highly sensitive the method that meets two criteria: ${ }^{62} 1$ ) The first criterion is $\mathrm{CV} \%$ when establishing the values of the 99th percentile should not exceed $10 \%$; 2) The second criterion is that the concentration of hs-cTnI and/or hs-cTnT must be higher than the LoD of this analytical method in more than $50 \%$ of healthy people, or in other words, the percentage of measurable values in healthy people must be above 50. However, despite these criteria, many methods labeled as highly sensitive do not fully meet these criteria. In addition, all journals, manufacturers, laboratories and institutions should use the ng/L unit to estimate hs-cTnI hs-cTnT levels to avoid confusion and decimal points followed by unnecessary zeros used in moderately sensitive and some modern highly sensitive assays. ${ }^{62}$

The clinical and diagnostic values of hs-TnT and hsTnI determination results depend directly on the analytical characteristics of the troponin immunoassays used, which should be taken into account by both researchers and practitioners (Table 1). The recommendations of the IFCC experts should be followed while calculating the analytical characteristics of cardiac troponin assays. ${ }^{62}$ For example, to establish 99th percentile values according to gender, troponin should be determined in at least 300 women and 300 men. Subsequently, they can be adjusted when new data are obtained, and ideally, each laboratory should establish its own 99th percentile, which, in this case, will correspond not only to the test and analyzer used in this particular laboratory but also to the specific features of the population in which the test is carried out. However, given the complexity and cost of such tests, it is acceptable to be guided by the parameters provided by the manufacturers. ${ }^{62,91}$ Establishing the optimal values of the 99th percentile is very important and involves a number of key questions, among which at least 2 aspects play a key role: 1) how should healthy patients be selected for reference groups? and 2) what statistical method for calculating the 99th percentile should be used? When discussing the first question, it should be clear which criteria should be used to select healthy individuals because in reality the definition of what a healthy person is can be a matter of debate. Also, selection of healthy individuals gives rise to an additional question about the need to take into account the age. Should young patients ( $<30$ years) be selected, or the ones of the age more likely to have AMI (50-90 years)? Possible criteria for selecting a reference population may include the following options: A) a simple questionnaire survey without physical and/or clinical studies and laboratory tests B) a complete physical examination, which may include only physical and/or a complete/partial set of laboratory tests and imaging studies (electrocardiography, echocardiography, determination of natriuretic peptide concentration, creatinine level and other biochemical and hemostasiology parameters). The second option, including the fullest possible set of laboratory tests and imaging studies, is ideal, but expensive. It has been shown that the selection of the reference group of patients according to stricter criteria shifts the 99th percentile towards lower values, ${ }^{103,104}$ which is probably caused by additional exclusion of patients suffering from latent or hard-todiagnose chronic diseases that have a negative effect on cardiomyocytes during superficial examination.

In the second question, concerning the establishment of the 99th percentile values, it is worth mentioning the necessity of using a unified statistical approach. For example, it has been shown that the proposed calculation methods - nonparametric method (Harrell-Davis method) and 
Table I Analytical Characteristics of Modern High-Sensitivity Methods Used to Determine hs-cTnl and hs-cTnT

\begin{tabular}{|c|c|}
\hline $\begin{array}{l}\text { Analytical Characteristics } \\
\text { of Troponin Immunoassay }\end{array}$ & $\begin{array}{l}\text { Definition and Brief } \\
\text { Description }\end{array}$ \\
\hline LoB & $\begin{array}{l}\text { Lowest signal generated in liquid } \\
\text { with zero concentration of } \\
\text { troponins (blank sample) - the } \\
\text { lower the better }\end{array}$ \\
\hline LoD & $\begin{array}{l}\text { Value obtained in the biofluid with } \\
\text { the lowest concentration of } \\
\text { troponin - the lower the better }\end{array}$ \\
\hline LoQ & $\begin{array}{l}\text { Minimum concentration that can be } \\
\text { determined with an error of } \leq 10 \% \text { - } \\
\text { the lower the better }\end{array}$ \\
\hline 99-percentile (general) & $\begin{array}{l}\text { Troponin concentration detected in } \\
99 \% \text { of truly healthy individuals, and } \\
\text { only I\% of truly healthy subjects } \\
\text { may have false positive results, } \\
\text { usually for some unknown reason }\end{array}$ \\
\hline 99-percentile (gender-specific) & $\begin{array}{l}\text { Troponin concentrations detected in } \\
99 \% \text { of healthy individuals, taking into } \\
\text { account gender. In men, the } 99 \text { th } \\
\text { percentile upper reference limit is } \\
\text { about } 1.5-2 \text { times higher than in } \\
\text { women, depending on the assay used }\end{array}$ \\
\hline $\begin{array}{l}\text { 99th percentile (age-related } \\
\text { and circadian features) - (?) }\end{array}$ & $\begin{array}{l}\text { Additional studies are needed to } \\
\text { clarify the existence of specific } \\
\text { features of the hs-cTnl and hs-cTnT } \\
\text { concentration in biofluids, } \\
\text { depending on the patient's age and } \\
\text { time of admission. }\end{array}$ \\
\hline Cut-off value & $\begin{array}{l}\text { Minimum troponin concentration } \\
\text { for diagnosis of AMI. This indicator } \\
\text { is used only in moderately sensitive } \\
\text { tests, whereas in accelerated } \\
\text { algorithms using high-and } \\
\text { ultrasensitive tests, the level of 99th } \\
\text { percentile is used as a reference. }\end{array}$ \\
\hline $\mathrm{CV} \%$ & $\begin{array}{l}\text { Random variation of measurements } \\
\text { in the same sample. The smaller it } \\
\text { is, the more accurate the assay is. }\end{array}$ \\
\hline $\begin{array}{l}\text { Percentile values }<\text { the 99th } \\
\text { percentile in healthy subjects }\end{array}$ & $\begin{array}{l}\text { Number of healthy individuals (in \%) } \\
\text { with detected troponin level in blood } \\
\text { between the LoD and 99th percentile. }\end{array}$ \\
\hline 99th percentile/LoD ratio & $\begin{array}{l}\text { The greater the number, the higher } \\
\text { the sensitivity of the assay }\end{array}$ \\
\hline
\end{tabular}

Abbreviations: Designations. AMI, acute myocardial infarction; hs-cTnl and hscTnT, high-sensitivity troponin I and T, respectively; LoB, limit of blank (false positive); LoD, limit of detection (minimum detectable concentration); LoQ, limit of quantitation (functional sensitivity); CV\%, coefficient of variation in \%. robust statistical method - give different values of the 99th percentile when using the same system and the same criteria for control population selection. ${ }^{104}$ The choice of the statistical method for calculating the 99th percentile is still a matter of debate. These aspects have a significant impact on the determination of the 99th percentile, and may explain the significant variations due to different approaches in its determination in the immunoassays of different manufacturers.

It is also important to note that some new rapid diagnostic algorithms for AMI (one- and two-hours) do not focus on the 99th percentile level as a reference diagnostic threshold but use lower cutoff values to decide on the need for hospitalization and/or invasive interventions. The reason is that many patients who have hs-Tn concentrations between the LoD (or LoQ) and the 99th percentile have a higher risk of adverse outcomes compared to those with minimal or no detectable values (ie, $<$ LoD or LoQ). The success of these strategies has been demonstrated in several studies for rapid exclusion of acute coronary syndrome and identification of patients at increased risk of 30-day major adverse cardiac events. ${ }^{105-110}$

LoD is very important in early diagnosis of AMI. For example, first- and second-generation immunoassay method had LoD in the range of $100-500 \mathrm{ng} / \mathrm{L}$ due to which AMI was diagnosed too late (12-24 h later); in some cases, smallfocal infarctions were missed and troponin was not detected in any healthy patient $(0 \%$ of measured values in the reference population). At the current stage of development of high-sensitivity assays, LoD can be only a few ng/L and even $<1 \mathrm{ng} / \mathrm{L}$, which is hundreds of times more sensitive and allows detecting myocardial damage almost at the level of single cells, and the percentage of healthy people with measurable hs-TnT and hs-TnI values ranges from $50 \%$ to $100 \% .{ }^{17,40}$ For instance, Garcia-Osuna et al have recently studied the analytical characteristics of a new method detecting hs-TnI at the level of single molecules. The study showed that this method has about 10 times higher sensitivity than other hs-TnI methods currently in use. The calculated LoD of this method was $0.08-0.12 \mathrm{ng} / \mathrm{L}$, and the percentage of healthy people with measurable hs-TnI concentrations reached $99.5 \%$. Healthy patients were selected according to very strict criteria, including a full set of imaging and laboratory methods (anamnesis, electrocardiography, normal levels of natriuretic peptides, creatinine, etc.). ${ }^{59}$ It is also very interesting to note that the median hscTnI was significantly higher in men compared to women 
and in the elderly compared to the young, which indicates the need to reflect not only gender but also age-related features in hs-cTnI levels when using this high-sensitivity immunoassay in clinical practice. This ultrasensitive immunoassay is significantly superior to other existing highsensitivity methods. ${ }^{59}$

$\mathrm{CV} \%$ - an important parameter that determines the accuracy of a high-sensitivity troponin immunoassay - is another analytical characteristic worth mentioning. A method is considered to be highly sensitive and highly accurate only if it meets certain IFCC requirements, ie the average variation of the results obtained should not exceed $10 \%(\mathrm{CV} \% \leq 10 \%)$ when determining in series the hs-TnT and hs-TnI levels in the same sample. However, ideally, the variation in high-sensitivity immunoassay values should be as low as possible and tend to zero. However, due to the low commercial availability of high-precision tests, many laboratories still use troponin immunoassays with a coefficient of variation of between $10 \%$ and $20 \%$. Some disadvantages of such tests may include false positive and false negative results due to the analytical side of the immunoassay, especially when the serum hs-TnT and hs-TnI levels in admitted patients are at borderline values. Tests with $\mathrm{CV}>20 \%$ are unacceptable for use in clinical practice and should be excluded (Table 2). Finally, in connection with the recent data, a significant improvement in the analytical characteristics of high-sensitivity tests, in particular a sharp decrease in LoD, made it possible to introduce an additional, so-called "functional" classification of methods based on a new criterion - the 99th percentile/LoD ratio. Moreover, the lower the 99th percentile/LoD ratio, the higher the probability of identifying subjects with measurable values, ie, the test is more sensitive. Hence, many researchers have introduced such terms as extremely sensitive and ultrasensitive to refer to immunoassays.

Some of the existing modern high-sensitivity tests approved by the IFCC for use in clinical practice, as well as their main analytical characteristics are summarized in Table 3. ${ }^{111}$ This table presents current data obtained in a number of recent studies on the possible existence of circadian rhythms and age-related features in hs-cTnI and hs-cTnT content for some tests. ${ }^{34,36,59,61,67-70,105-110}$ As noted above, the influence of circadian and age-related features on the diagnosis of CVD and AMI is still poorly understood and requires further research and clarification of specific numerical indicators.
Table 2 Analytical Characteristics of the Accuracy and Sensitivity of Highly Sensitive Methods of Cardiac Troponin Detection

\begin{tabular}{|c|c|}
\hline \multicolumn{2}{|c|}{$\begin{array}{c}\text { Coefficient of Variation (Assay Inaccuracy in \%) of High- } \\
\text { Sensitivity Immunoassays (hs-cTnI and hs-cTnT) }\end{array}$} \\
\hline CV\% value & Brief Description, Comment \\
\hline CV\% $\leq 10$ & High-precision (most preferred for clinical use) \\
\hline $10 \leq$ CV\% $\leq 20$ & Non-high accuracy, but acceptable for clinical use \\
\hline CV\% $\geq 20$ & Inaccurate, and unacceptable for clinical use \\
\hline Percentile (\%) of measurable values < 99th percentile in \\
healthy subjects
\end{tabular}

Abbreviations: Designations. hs-cTnl and hs-cTnT, high-sensitivity troponin I and $\mathrm{T}$, respectively; LoD, limit of detection (minimum detectable concentration); $\mathrm{CV} \%$, coefficient of variation in \%.

\section{Early Diagnostic Algorithms (0-I h, 0-2 $\mathrm{h}$, and $0-3 \mathrm{~h}$ ) for Quick Exclusion/ Confirmation of AMI}

Several effective early diagnostic algorithms for quick exclusion/confirmation of AMI have been proposed in accordance with the results of large clinical studies $^{110,112-121}$ (Figures 2 and 3).

\section{Some Directions for Future Research}

In accordance with the biochemical data outlined above and the diagnostic capabilities of hs-cTnI and hs-cTnT, further studies are needed to clarify information on the biological features of cardiac troponins, in particular to clarify information on the existence of extracardiac expression of cardiac troponin, to clarify information on the existence and clinical significance of age-related features and circadian rhythms in the levels of cardiac 
Table 3 Analytical Characteristics of hs-cTnl and hs-cTnT High-Sensitivity Immunoassays Provided by Manufacturers (as Reported by the IFCC Committee on Clinical Applications of Cardiac Bio-Markers "II as Amended)

\begin{tabular}{|c|c|c|c|c|c|c|c|}
\hline $\begin{array}{l}\text { Company/ } \\
\text { Platform/Method }\end{array}$ & $\begin{array}{l}\text { LoB } \\
\text { (ng/l) }\end{array}$ & $\begin{array}{l}\text { LoD } \\
\text { (ng/l) }\end{array}$ & $\begin{array}{l}\text { CV } \\
\%\end{array}$ & $\begin{array}{l}\text { 99th- } \\
\text { Percentile } \\
\text { (General } \\
\text { and by } \\
\text { Gender), } \\
\text { ng/l }\end{array}$ & $\begin{array}{l}\text { 99th-Percentile } \\
\text { (According to } \\
\text { Age-Related and } \\
\text { Circadian } \\
\text { Features), } \pm\end{array}$ & $\begin{array}{l}\text { Percentage of Measurable } \\
\text { Values in the Range from } \\
\text { LoD to 99th-Percentile } \\
\text { (General and by Gender, } \\
\% \text { ) }\end{array}$ & $\begin{array}{l}\text { Statistical } \\
\text { Method Used } \\
\text { to Calculate } \\
\text { the 99th- } \\
\text { Percentile }\end{array}$ \\
\hline $\begin{array}{l}\text { Abbott/Alinity } \\
\text { i systems/Alinity } \\
\text { i STAT High Sensitive } \\
\text { Troponin-l; } \\
\text { commercial OUS }\end{array}$ & $\mathrm{I}, 0$ & 1,6 & 4,0 & $\begin{array}{l}\text { General- } \\
26,2 \\
\text { F-I5,6 } \\
\text { M-34,2 }\end{array}$ & $\begin{array}{l}99 \text { percentile (age- } \\
\text { related): }+ \\
99 \text { percentile } \\
\text { (circadian- } \pm\end{array}$ & $\begin{array}{l}\text { General-85\% } \\
\text { F-78\% } \\
\text { M-92\% }\end{array}$ & $\begin{array}{l}\text { Robust- } \\
\text { statistics }\end{array}$ \\
\hline $\begin{array}{l}\text { Abbott/ARCHITECT } \\
\text { i systems/ } \\
\text { ARCHITECT STAT } \\
\text { High Sensitive } \\
\text { Troponin-l; } \\
\text { commercial }\end{array}$ & $0,7-1,3$ & $\mathrm{I}, \mathrm{I}$ & 4,0 & $\begin{array}{l}\text { General } \\
-26,2 \\
\text { F-15,6 } \\
\text { M-34,2 }\end{array}$ & $\begin{array}{l}99 \text { percentile (age- } \\
\text { related):+ } \\
99 \text { percentile } \\
\text { (circadian:士 }\end{array}$ & $\begin{array}{l}\text { General-85\% } \\
\text { F-78\% } \\
\text { M-92 }\end{array}$ & $\begin{array}{l}\text { Robust- } \\
\text { statistics }\end{array}$ \\
\hline $\begin{array}{l}\text { Beckman Coulter/ } \\
\text { Access 2, Dxl/Access } \\
\text { hsTnl; commercial - } \\
\text { OUS }\end{array}$ & $0,0-1,7$ & $\mathrm{I}, 0-2,3$ & 3,7 & $\begin{array}{l}\text { General } \\
-I 7,5 \\
\text { F-II,6 } \\
\text { M-I9,8 }\end{array}$ & $\begin{array}{l}99 \text { percentile (age- } \\
\text { related):- } \\
99 \text { percentile } \\
\text { (circadian:- }\end{array}$ & $>50$ & $\begin{array}{l}\text { Non- } \\
\text { Parametric }\end{array}$ \\
\hline $\begin{array}{l}\text { Beckman Coulter/ } \\
\text { Access 2, /Access } \\
\text { hsTnl; commercial - } \\
\text { US: Serum }\end{array}$ & $0,0-0,8$ & $\mathrm{I}, 0-2,0$ & 6,0 & $\begin{array}{l}\text { General } \\
-I 8,2 \\
\text { F-II,8 } \\
\text { M- } 19,7\end{array}$ & $\begin{array}{l}99 \text { percentile (age- } \\
\text { related):- } \\
99 \text { percentile } \\
\text { (circadian:- }\end{array}$ & $>50$ & $\begin{array}{l}\text { Non- } \\
\text { Parametric }\end{array}$ \\
\hline $\begin{array}{l}\text { LSI Medience } \\
\text { (formerly Mitsubishi) } \\
\text { PATHFAST hs-cTnl; } \\
\text { commercial }\end{array}$ & $\begin{array}{l}\text { Not } \\
\text { provided }\end{array}$ & I & $<6$ & $\begin{array}{l}\text { General } \\
-I 5,48 \\
\text { F-I6,9I } \\
\text { M-II,46 }\end{array}$ & $\begin{array}{l}99 \text { percentile (age- } \\
\text { related):- } \\
99 \text { percentile } \\
\text { (circadian:- }\end{array}$ & General-76 & $\begin{array}{l}\text { Non- } \\
\text { Parametric }\end{array}$ \\
\hline $\begin{array}{l}\text { LSI Medience (former } \\
\text { Mitsubishi) PATHFAST } \\
\text { hs-cTnl /PATHFAST } \\
\text { cTnl-II }\end{array}$ & 1,23 & 2,33 & 6,1 & $\begin{array}{l}\text { General- } \\
27,9 \\
\text { F-20,3 } \\
\text { M-29,7 }\end{array}$ & $\begin{array}{l}99 \text { percentile (age- } \\
\text { related):- } \\
99 \text { percentile } \\
\text { (circadian:- }\end{array}$ & $\begin{array}{l}\text { General-66.3 } \\
\text { F-52,8 } \\
\text { M-78,8 }\end{array}$ & $\begin{array}{l}\text { Non- } \\
\text { Parametric }\end{array}$ \\
\hline $\begin{array}{l}\text { Ortho/VITROS/ } \\
\text { hsTroponin I; } \\
\text { commercial }\end{array}$ & $0,|4-0,5|$ & $0,39-0,86$ & $<10$ & $\begin{array}{l}\text { General- } \\
11,0 \\
\text { F-9,0 } \\
\text { M-I } 2,0\end{array}$ & $\begin{array}{l}99 \text { percentile (age- } \\
\text { related):- } \\
99 \text { percentile } \\
\text { (circadian:- }\end{array}$ & $>50$ & $\begin{array}{l}\text { Non- } \\
\text { Parametric }\end{array}$ \\
\hline $\begin{array}{l}\text { Roche/cobas e80I/ } \\
\text { cTnT-hs I8-min and } \\
\text { STAT; commercial }\end{array}$ & 2,5 & 3 & $<10$ & $\begin{array}{l}\text { General- } \\
14,0 \\
\text { F-9,0 } \\
\text { M-I6,0 }\end{array}$ & $\begin{array}{l}99 \text { percentile (age- } \\
\text { related):- } \\
99 \text { percentile } \\
\text { (circadian:+ }\end{array}$ & General-57,4 & $\begin{array}{l}\text { Non- } \\
\text { Parametric }\end{array}$ \\
\hline $\begin{array}{l}\text { Roche/cobas e60I, } \\
\text { e602, EI70/cTnT-hs } \\
\text { I8-min; commercial }\end{array}$ & 1,36 & 2,05 & $<10$ & $\begin{array}{l}\text { General- } \\
14,0 \\
\text { F-9,0 } \\
\text { M-I6,0 }\end{array}$ & $\begin{array}{l}99 \text { percentile (age- } \\
\text { related): } \pm \\
99 \text { percentile } \\
\text { (circadian:+ }\end{array}$ & General-7।,5 & $\begin{array}{l}\text { Non- } \\
\text { Parametric }\end{array}$ \\
\hline
\end{tabular}

(Continued) 
Table 3 (Continued).

\begin{tabular}{|c|c|c|c|c|c|c|c|}
\hline $\begin{array}{l}\text { Company/ } \\
\text { Platform/Method }\end{array}$ & $\begin{array}{l}\text { LoB } \\
\text { (ng/l) }\end{array}$ & $\begin{array}{l}\text { LoD } \\
\text { (ng/l) }\end{array}$ & $\begin{array}{l}\text { CV } \\
\%\end{array}$ & $\begin{array}{l}\text { 99th- } \\
\text { Percentile } \\
\text { (General } \\
\text { and by } \\
\text { Gender), } \\
\text { ng/l }\end{array}$ & $\begin{array}{l}\text { 99th-Percentile } \\
\text { (According to } \\
\text { Age-Related and } \\
\text { Circadian } \\
\text { Features), } \pm\end{array}$ & $\begin{array}{l}\text { Percentage of Measurable } \\
\text { Values in the Range from } \\
\text { LoD to 99th-Percentile } \\
\text { (General and by Gender, } \\
\% \text { ) }\end{array}$ & $\begin{array}{l}\text { Statistical } \\
\text { Method Used } \\
\text { to Calculate } \\
\text { the 99th- } \\
\text { Percentile }\end{array}$ \\
\hline $\begin{array}{l}\text { Siemens ADVIA } \\
\text { Centaur XP/ XPT } \\
\text { HighSensitivity Tnl } \\
\text { (TNIH), US \& OUS; } \\
\text { commercial }\end{array}$ & 0,50 & 1,6 & $<4,9$ & $\begin{array}{l}\text { General- } \\
46,5 \\
\text { F-39,6 } \\
\text { M-58,0 }\end{array}$ & $\begin{array}{l}99 \text { percentile (age- } \\
\text { related): } \pm \\
99 \text { percentile } \\
\text { (circadian:- }\end{array}$ & $\begin{array}{l}\text { General-72,0 } \\
\text { F-57,0 } \\
\text { M-86,0 }\end{array}$ & $\begin{array}{l}\text { Non- } \\
\text { Parametric }\end{array}$ \\
\hline $\begin{array}{l}\text { Siemens Dimension } \\
\text { VISTA High Sensitivity } \\
\text { Tnl (TNIH), OUS; } \\
\text { commercial }\end{array}$ & $\mathrm{I}, 0$ & 2,0 & $<5$ & $\begin{array}{l}\text { General- } \\
58,9 \\
\text { F-53,7 } \\
\text { M-78,5 }\end{array}$ & $\begin{array}{l}99 \text { percentile (age- } \\
\text { related):- } \\
99 \text { percentile } \\
\text { (circadian:- }\end{array}$ & $\begin{array}{l}\text { General-72,0 } \\
\text { F-not provided } \\
\text { M-not provided }\end{array}$ & $\begin{array}{l}\text { Non- } \\
\text { Parametric }\end{array}$ \\
\hline $\begin{array}{l}\text { Singulex Clarity cTnl; } \\
\text { commercial }\end{array}$ & 0,02 & 0,08 & 2,39 & $\begin{array}{l}\text { General- } \\
8,67 \\
\text { F-8,76 } \\
\text { M-9,23 }\end{array}$ & $\begin{array}{l}99 \text { percentile (age- } \\
\text { related):+ } \\
99 \text { percentile } \\
\text { (circadian:- }\end{array}$ & $\begin{array}{l}\text { General-99 } \\
\text { F-99 } \\
\text { M-100 }\end{array}$ & $\begin{array}{l}\text { Non- } \\
\text { Parametric }\end{array}$ \\
\hline
\end{tabular}

Notes: Designation in the 99th percentile column (according to age-related and circadian features), + present, “+l-" - doubtful (data are contradictory), “-” - absent or not studied.

Abbreviations: Designations. hs-cTnl and hs-cTnT, high-sensitivity troponin I and T, respectively; M, men; F, female; LoB, limit of blank (false positive); LoD, limit of detection (minimum detectable concentration); LoQ, limit of quantitation (functional sensitivity); CV \%, coefficient of variation in \%.

troponins, to study the processes of intra- and extracellular molecule cleavage and the influence of various factors on them, in particular the components of hemostasis system, ${ }^{96}$ the degree of ischemia, ${ }^{94}$ the activity of adrenergic system $^{26,97}$ and some others. Understanding these peculiarities will help to improve immunochemical methods of hs-cTnI and hs-cTnT detection, for example, by introducing additional reagents in tests that inhibit certain enzymes that cause cleavage of the troponin proteins being determined. And consideration of circadian and agerelated features in the serum content of hs-cTnI and hscTnT will optimize the early diagnosis of AMI and screening patients for CVD, taking into account the patient's age and time of admission.

The study of hs-cTnI and hs-cTnT molecules in biofluids obtained by non-invasive methods, in particular, in urine and oral fluid has very promising possibilities. ${ }^{76-78}$ However, the existing studies are still insufficient to fully understand their practical significance for the laboratory diagnosis of CVD and there is an urgent need for further research.

Finally, it becomes obvious that the diagnostic value of hs-cTnI and hs-cTnT goes far beyond the diagnosis of AMI. Recent studies have shown that hs-cTnI and hs-
cTnT can be a valuable tool for detection of myocardial damage in healthy patients in the early stages of CVD formation, ${ }^{122,123}$ as well as in patients suffering from a very extensive list of nosologies, including sepsis, ${ }^{46,47,55}$ myocarditis, ${ }^{43,44,124}$ chronic obstructive pulmonary disease, ${ }^{125}$ recently appeared and already recognized as one of the most common viral infections COVID- $19^{126}$ and other conditions (for more detailed list of conditions see Figure 1), thus having some prognostic value, which may allow to identify patients who need a more thorough examination and implementation of a set of preventive and therapeutic measures to improve the duration and quality of their lives.

\section{Conclusion}

The introduction of highly sensitive methods for the determination of cardiac troponins (hs-cTnI and hs-cTnT) has significantly changed our understanding of the biology and diagnostic capabilities of these laboratory biomarkers. For the most effective use of hs-cTnI and hs-cTnT, the basic analytical characteristics of high-sensitivity assays should be considered, including limit of blank, limit of detection (minimum detectable concentration), coefficient of variation, general and gender-specific 99th percentile, 99th percentile/ 


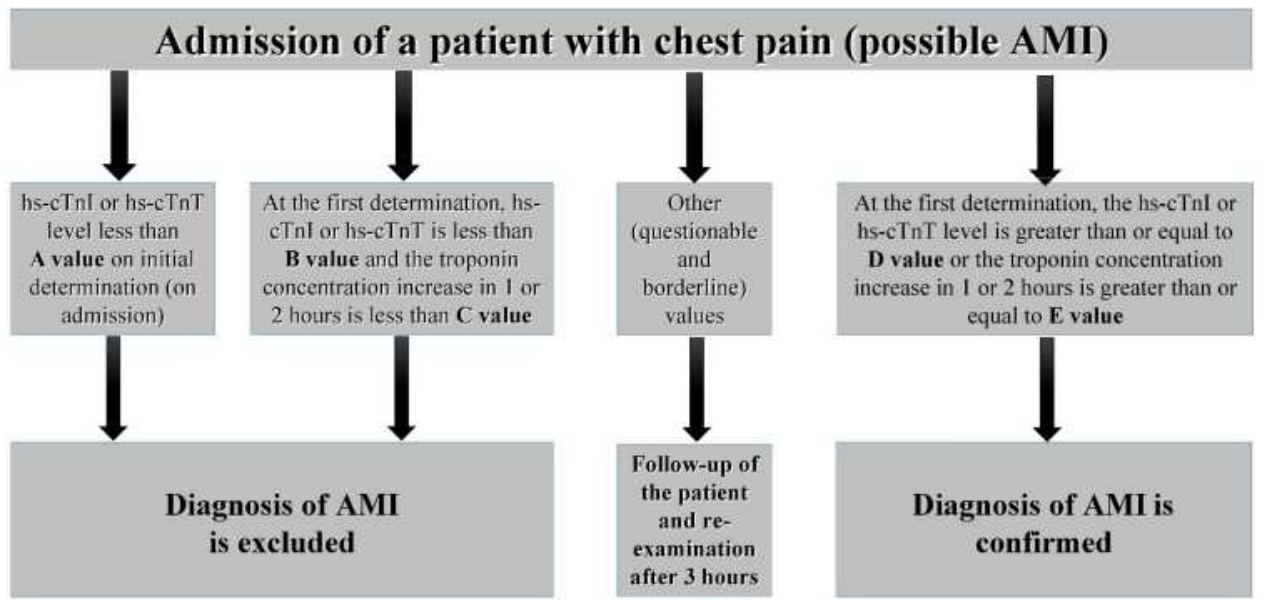

\begin{tabular}{|c|c|c|c|c|c|}
\hline & \multicolumn{5}{|c|}{ T arget hs-cTnI and hs-cTnT values for various tests, ng/L } \\
\hline $\begin{array}{l}\text { Repeated } \\
\text { determination of } \\
\text { serum biomarker } \\
\text { levels after } 1 \text { hour }\end{array}$ & A & B & $\mathrm{C}$ & D & $\mathrm{E}$ \\
\hline $\begin{array}{l}\text { hs-cTnT (Roche } \\
\text { Diagnostics) }\end{array}$ & 5 & 12 & 3 & 52 & 5 \\
\hline $\begin{array}{l}\text { hs-cTnI (Beckman } \\
\text { Coulter) }\end{array}$ & 4 & 5 & 4 & 50 & 15 \\
\hline hs-cTnI (A bbot) & 4 & 5 & 2 & 64 & 6 \\
\hline $\begin{array}{l}\text { Repeated } \\
\text { determination of } \\
\text { serum biomarker } \\
\text { levels after } 2 \text { hours }\end{array}$ & & & & & \\
\hline $\begin{array}{l}\text { hs-cTnT (Roche } \\
\text { Diagnostics) }\end{array}$ & 5 & 14 & 4 & 52 & 10 \\
\hline $\begin{array}{l}\text { hs-cTnI (Beckman } \\
\text { Coulter) }\end{array}$ & 4 & 5 & 5 & 50 & 15 \\
\hline hs-cTnI (Abbot) & 4 & 6 & 2 & 64 & 15 \\
\hline
\end{tabular}

Figure 2 Early diagnostic algorithms $0-\mathrm{I} h$ and $0-2 \mathrm{~h}$ for exclusion/confirmation of AMI by hs-cTnl and hs-cTnT levels for some tests.

Notes: If it is not possible to confirm/exclude AMI after two studies in dynamics (0-I or 0-2 hours), it is recommended to conduct additional studies of hs-cTnl and hscTnT levels after 3 and/or 6 hours.

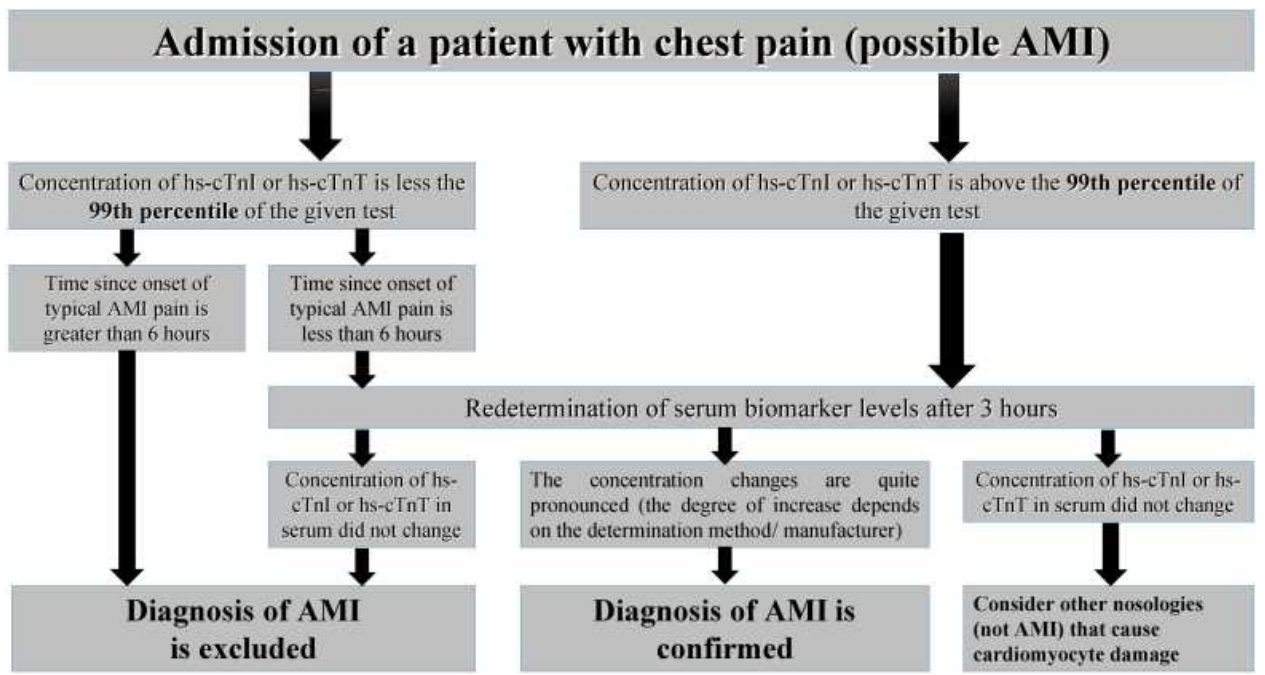

Figure 3 Early diagnostic algorithm 0-3 h to exclude/confirm AMl by hs-cTnl and hs-cTnT levels.

Notes: 99th percentile value depends on the method of determination (manufacturer) 
limit of detection ratio. The need to take into account the 99th percentile with consideration of age-related and circadian features remains in question and requires further study. Since more and more manufacturers produce tests based on highly sensitive detection methods, there is a need for independent analytical and clinical evaluations of these methods.

\section{Disclosure}

The author reports no conflicts of interest in this work.

\section{References}

1. Ohtsuki I, Morimoto S. Troponin: regulatory function and disorders. Biochem Biophys Res Commun. 2008;369(1):62-73. doi:10.1016/j.bbrc.2007.11.187

2. Ohtsuki I. Troponin: structure, function and dysfunction. $A d v \operatorname{Exp}$ Med Biol. 2007;592:21-36. doi:10.1007/978-4-431-38453-3_4

3. Mogensen J. Troponin mutations in cardiomyopathies. $A d v$ Exp Med Biol. 2007;592:201-226. doi:10.1007/978-4-431-38453-3_18

4. Luo J, Zhao W, Gan Y, et al. Cardiac troponin I R193H mutation is associated with mitochondrial damage in cardiomyocytes. DNA Cell Biol. 2021;40(2):184-191. doi:10.1089/dna.2020.5828

5. Pasquale F, Syrris P, Kaski JP, et al. Long-term outcomes in hypertrophic cardiomyopathy caused by mutations in the cardiac troponin T gene. Circ Cardiovasc Genet. 2012;5(1):10-17. doi:10.1161/CIRCGENETICS.111.959973

6. Tobacman LS, Cammarato A. Cardiomyopathic troponin mutations predominantly occur at its interface with actin and tropomyosin. $J$ Gen Physiol. 2021;153(3):e202012815. doi:10.1085/jgp.202012815

7. Morimoto S. Molecular pathogenic mechanisms of cardiomyopathies caused by mutations in cardiac troponin T. Adv Exp Med Biol. 2007;592:227-239. doi:10.1007/978-4-431-38453-3_19

8. Duplyakov DV, Chaulin AM. Mutations of heart troponines, associated with cardiomyopathies. Kardiologiya: Novosti, Mneniya, Obuchenie [Cardiology: News, Opinions, Training]. 2019;7(3):8-17. In Russian. doi:10.24411/2309-1908-2019-13001

9. Katruha IA. Troponin complex of the human heart. Structure and functions. Adv Biol Chem. 2013;53:149-194. In Russian.

10. Chaulin AM, Duplyakov DV. Biomarkers of acute myocardial infarction: diagnostic and prognostic value. Part 1. J Clin Pract. 2020;11(4):75-84. In Russian. doi:10.17816/clinpract48893

11. Ricchiuti V, Apple FS. RNA expression of cardiac troponin $\mathrm{T}$ isoforms in diseased human skeletal muscle. Clin Chem. 1999;45(12):2129-2135. doi:10.1093/clinchem/45.12.2129

12. McLaurin MD, Apple FS, Voss EM, et al. Cardiac troponin I, cardiac troponin $\mathrm{T}$, and creatine kinase $\mathrm{MB}$ in dialysis patients without ischemic heart disease: evidence of cardiac troponin $\mathrm{T}$ expression in skeletal muscle. Clin Chem. 1997;43 (6):976-982. doi:10.1093/clinchem/43.6.976

13. Ricchiuti V, Voss EM, Ney A, et al. Cardiac troponin T isoforms expressed in renal diseased skeletal muscle will not cause false-positive results by the second generation cardiac troponin $\mathrm{T}$ assay by Boehringer Mannheim. Clin Chem. 1998;44 (9):1919-1924. doi:10.1093/clinchem/44.9.1919

14. Messner B, Baum H, Fischer P, et al. Expression of messenger RNA of the cardiac isoforms of troponin $\mathrm{T}$ and $\mathrm{I}$ in myopathic skeletal muscle. Am J Clin Pathol. 2000;114(4):544-549. doi:10.1309/8KCL-UQRF-6EEL-36XK

15. Wens SCA, Schaaf GJ, Michels M, et al. Elevated plasma cardiac troponin $\mathrm{T}$ levels caused by skeletal muscle damage in Pompe disease. Circ Cardiovasc Genet. 2016;9(1):6-13. doi:10.1161/ CIRCGENETICS.115.001322
16. Apple FS. Tissue specificity of cardiac troponin I, cardiac troponin T and creatine kinase-MB. Clin Chim Acta. 1999;284 (2):151-159. doi:10.1016/s0009-8981(99)00077-7

17. Rusakov DY, Vologdina NN, Tulayeva ON. The development of striated cardiac muscle tissue in the walls of the caval and pulmonary veins. J Anatomy Histopathol. 2015;4(3):105. In Russian. doi:10.18499/2225-7357-2015-4-3-105-105

18. Cavalcanti JS, Santos LP. Morphofunctional study of the junction between the left atrium and the pulmonary veins in patient with pulmonary hypertension. Arq Bras Cardiol. 2001;77(3):229-234. English, Portuguese. doi:10.1590/s0066-782×2001000900003

19. Hammerer-Lercher A, Erlacher P, Bittner R, et al. Clinical and experimental results on cardiac troponin expression in Duchenne muscular dystrophy. Clin Chem. 2001;47(3):451-458. doi:10.1093/clinchem/47.3.451

20. Schmid J, Liesinger L, Birner-Gruenberger R, et al. Elevated cardiac troponin $\mathrm{T}$ in patients with skeletal myopathies. $\mathrm{J} \mathrm{Am} \mathrm{Coll} \mathrm{Cardiol.}$ 2018;71(14):1540-1549. doi:10.1016/j.jacc.2018.01.070

21. Dhoot GK, Gell PG, Perry SV. The localization of the different forms of troponin I in skeletal and cardiac muscle cells. Exp Cell Res. 1978;117(2):357-370. doi:10.1016/0014-4827(78)90149-0

22. Dhoot GK, Perry SV. Distribution of polymorphic forms of troponin components and tropomyosin in skeletal muscle. Nature. 1979;278(5706):714-718. doi:10.1038/278714a0

23. Filatov VL, Katruha AG, Bulargina TV, et al. Troponin: structure, properties and mechanism of functioning. Biochemistry. 1999;64 (9):1155-1174. In Russian.

24. Chaulin AM, Karslyan LS, Bazyuk EV, et al. [Clinical and diagnostic value of cardiac markers in human biological fluids]. Kardiologiia. 2019;59(11):66-75. In Russian. doi:10.18087/cardio.2019.11.n414

25. Velkov VV, Opredelentseva SV, Shvidenko IG, Norkin IA, Korshunov GV, Gladkova EV. The new international criteria of cardiac infarction and highly sensitive troponins: new possibilities and new problems. Klin Lab Diagn. 2014;59(8):43-53. In Russian.

26. Feng J, Schaus BJ, Fallavollita JA, et al. Preload induces troponin I degradation independently of myocardial ischemia. Circulation. 2001;103(16):2035-2037. doi:10.1161/01.cir.103.16.2035

27. Chaulin AM, Duplyakov DV. Increased cardiac troponins, not associated with acute coronary syndrome. Part 1. Kardiologiya: Novosti, Mneniya, Obuchenie [Cardiology: News, Opinions, Training]. 2019;7(2):13-23. In Russian. doi:10.24411/23091908-2019-12002

28. Chaulin AM, Duplyakov DV. Increased cardiac troponins, not associated with acute coronary syndrome. Part 2. Kardiologiya: Novosti, Mneniya, Obuchenie [Cardiology: News, Opinions, Training]. 2019;7(2):24-35. In Russian. doi:10.24411/23091908-2019-12003

29. Vafaie M. State-of-the-art diagnosis of myocardial infarction. Diagnosis (Berl). 2016;3(4):137-142. doi:10.1515/dx-2016-0024

30. Thygesen K, Alpert JS, Jaffe AS, et al.; Executive Group on behalf of the Joint European Society of Cardiology (ESC)/ American College of Cardiology (ACC)/American Heart Association (AHA)/World Heart Federation (WHF) Task Force for the Universal Definition of Myocardial Infarction. Fourth universal definition of myocardial infarction (2018). Glob Heart. 2018;13(4):305-338. doi:10.1016/j.gheart.2018.08.004.

31. Chaulin AM, Duplyakov DV. Biomarkers of acute myocardial infarction: diagnostic and prognostic value. Part 2 (literature review). $J$ Clin Pract. 2020;11(4):70-82. doi:10.17816/ clinpract 48893

32. Kelley WE, Januzzi JL, Christenson RH. Increases of cardiac troponin in conditions other than acute coronary syndrome and heart failure. Clin Chem. 2009;55(12):2098-2112. doi:10.1373/ clinchem.2009.130799 
33. Chaulin AM, Karslyan LS, Duplyakov DV. Non-coronarogenic causes of increased cardiac troponins in clinical practice. J Clin Pract. 2019;10(4):81-93. In Russian. doi:10.17816/clinpract16309

34. Chaulin AM, Svechkov NA, Volkova SL, Grigoreva YV. Diagnostic value of cardiac troponins in elderly patients without myocardial infarction. Mod Prob Sci Educ. 2020;6. doi:10.17513/ spno.30302.

35. Long B, Long DA, Tannenbaum L, Koyfman A. An emergency medicine approach to troponin elevation due to causes other than occlusion myocardial infarction. Am J Emerg Med. 2020;38 (5):998-1006. doi:10.1016/j.ajem.2019.12.007

36. Chaulin AM, Duplyakov DV. On the potential effect of circadian rhythms of cardiac troponins on the diagnosis of acute myocardial infarction. Signa Vitae. 2021. doi:10.22514/sv.2021.050

37. Xue F, Jiang TB, Jiang B, et al. Cardiac troponin I elevation with supraventricular tachycardia: two case reports and review of the literature. BMC Res Notes. 2014;7:136. doi:10.1186/1756-05007-136

38. Manjunath L, Yeluru A, Rodriguez F. 27-year-old man with a positive troponin: a case report. Cardiol Ther. 2018;7 (2):197-204. doi:10.1007/s40119-018-0120-3

39. Lum G, Solarz DE, Farney L. False positive cardiac troponin results in patients without acute myocardial infarction. Lab Med. 2006;37(9):546-550. doi:10.1309/T94UUXTJ3TX5Y9W2

40. Marinheiro R, Amador P, Parreira L, et al. False positive troponin I rendering two admissions for "recurrent acute myopericarditis". Open Cardiovasc Med J. 2018;12:55-58. doi:10.2174/ 1874192401812010055

41. Richardson AJ, Leckie T, Watkins ER, et al. Post marathon cardiac troponin $\mathrm{T}$ is associated with relative exercise intensity. $\mathrm{J} \mathrm{Sci} \mathrm{Med}$ Sport. 2018;21(9):880-884. doi:10.1016/j.jsams.2018.02.005

42. Lazzarino AI, Hamer M, Gaze D, et al. The association between cortisol response to mental stress and high sensitivity cardiac troponin $\mathrm{T}$ plasma concentration in healthy adults. $\mathrm{J} \mathrm{Am}$ Coll Cardiol. 2013;62(18):1694-1701. doi:10.1016/j.jacc.2013.05.070

43. Lauer B, Niederau C, Kuhl U, et al. Cardiac troponin T in patients with clinically suspected myocarditis. J Am Coll Cardiol. 1997;30 (5):1354-1359. doi:10.1016/S0735-1097(97)00317-3

44. Ukena C, Kindermann M, Mahfoud F, et al. Diagnostic and prognostic validity of different biomarkers in patients with suspected myocarditis. Clin Res Cardiol. 2014;103(9):743-751. doi:10.1007/s00392-014-0709-z

45. Kumar A, Kumar A, Paladugu B, et al. Transforming growth factor-beta 1 blocks in vitro cardiac myocyte depression induced by tumour necrosis factor-alpha, interleukin-1 beta, and human septic shock serum. Crit Care Med. 2007;35(2):358-364. doi:10.1097/01.CCM.0000254341.87098.A4

46. Bessiere F, Khenifer S, Dubourg J, et al. Prognostic value of troponins in sepsis: a meta-analysis. Intensive Care Med. 2013;39(7):1181-1189. doi:10.1007/s00134-013-2902-3

47. Rosjo H, Varpula M, Hagve TA, et al. Circulating high-sensitive troponin $\mathrm{T}$ in severe sepsis and septic shock: distribution, associated factors, and relation to outcome. Intensive Care Med. 2011;37(1):77-85. doi:10.1007/s00134-010-2051-x

48. Dubin RF, Li Y, He J, et al. Predictors of high sensitivity cardiac troponin $\mathrm{T}$ in chronic kidney disease patients: a cross-sectional study in the chronic renal insufficiency cohort (CRIC). BMC Nephrol. 2013;14:229. doi:10.1186/1471-2369-14-229

49. Zumrutdal AO, Bakinen O, Ucan H, et al. Relationship between uremic myopathy and false-positive cardiac troponin $\mathrm{T}$ test. Nephron. 2000;86:522-523. doi:10.1159/000045852

50. Chesnaye NC, Szummer K, Bárány P, et al.; EQUAL Study Investigators $\dagger$; EQUAL Study Investigators $\dagger$. Association between renal function and troponin $\mathrm{T}$ over time in stable chronic kidney disease patients. J Am Heart Assoc. 2019;8(21):e013091. doi:10.1161/JAHA.119.013091
51. Bukkapatnam RN, Robinson M, Turnipseed S, et al. Relationship of myocardial ischemia and injury to coronary artery disease in patients with supraventricular tachycardia. Am $J$ Cardiol. 2010;106(3):374-377. doi:10.1016/j.amjcard.2010.03.035

52. Zellweger MJ, Schaer BA, Cron TA, et al. Elevated troponin levels in absence of coronary artery disease after supraventricular tachycardia. Swiss Med Wkly. 2003;133(31-32):439-441.

53. Chaulin AM, Duplyakov DV. MicroRNAs in atrial fibrillation: pathophysiological aspects and potential biomarkers. Int J Biomed. 2020;10(3):198-205. doi:10.21103/Article10(3) RA3

54. Chaulin AM, Abashina OE, Duplyakov DV. Pathophysiological mechanisms of cardiotoxicity in chemotherapeutic agents. Russ Open Med J. 2020;9:e0305. doi:10.15275/rusomj.2020.0305

55. Wilhelm J, Hettwer S, Schuermann M, et al. Elevated troponin in septic patients in the emergency department: frequency, causes, and prognostic implications. Clin Res Card. 2014;103 (7):561-567. doi:10.1007/s00392-014-0684-4

56. Maekawa A, Lee JK, Nagaya T, et al. Overexpression of calpastatin by gene transfer prevents troponin I degradation and ameliorates contractile dysfunction in rat hearts subjected to ischemia/ reperfusion. J Mol Cell Cardiol. 2003;35(10):1277-1284. doi:10.1016/s0022-2828(03)00238-4

57. O'Hanlon R, Wilson M, Wage R, et al. Troponin release following endurance exercise: is inflammation the cause? A cardiovascular magnetic resonance study. J Cardiovasc Magn Reson. 2010;12(1):38. doi:10.1186/1532-429X-12-38

58. Chaulin AM, Karslyan LS, Grigorieva EV, et al. Metabolism of cardiac troponins (literature review). Complex Issues Cardiovasc Dis. 2019;8(4):103-115. In Russian. doi:10.17802/2306-12782019-8-4-103-115

59. Garcia-Osuna A, Gaze D, Grau-Agramunt M, et al. Ultrasensitive quantification of cardiac troponin I by a single molecule counting method: analytical validation and biological features. Clin Chim Acta. 2018;486:224-231. doi:10.1016/j.cca.2018.08.015

60. Apple FS. The specificity of biochemical markers of cardiac damage: a problem solved. Clin Chem Lab Med. 1999;37(11-12):1085-1089. doi:10.1515/CCLM.1999.158

61. Chaulin AM, Duplyakova PD, Duplyakov DV. Circadian rhythms of cardiac troponins: mechanisms and clinical significance. Russ J Cardiol. 2020;25(3):4061. doi:10.15829/ 1560-4071-2020-4061

62. Shah A, Griffiths M, Lee KK, et al. High sensitivity cardiac troponin and the under-diagnosis of myocardial infarction in women. BMJ. 2015;350:g7873. doi:10.1136/bmj.g7873

63. Apple FS, Jaffe AS, Collinson P, et al. IFCC educational materials on selected analytical and clinical applications of high sensitivity cardiac troponin assays. Clin Biochem. 2015;48(4-5):201203. doi:10.1016/j.clinbiochem.2014.08.021

64. Cediel G, Codina P, Spitaleri G, et al. Gender-related differences in heart failure biomarkers. Front Cardiovasc Med. 2021;7:617705. doi:10.3389/fcvm.2020.617705

65. Gore MO, Seliger SL, deFilippi CR, et al. Age- and sex-dependent upper reference limits for the high-sensitivity cardiac troponin T assay. J Am Coll Cardiol. 2014;63:1441-1448. doi:10.1016/j.jacc.2013.12.032

66. Trupp RJ, Albert G, Ziegler A. Sex-specific 99th percentiles derived from the AACC universal sample bank for the roche gen 5 cTnT assay: comorbidities and statistical methods influence derivation of reference limits. Clin Biochem. 2018;52:173. doi:10.1016/j.clinbiochem.2017.11.003

67. Klinkenberg LJJ, Wildi K, van der Linden N, et al. Diurnal rhythm of cardiac troponin: consequences for the diagnosis of acute myocardial infarction. Clin Chem. 2016;62(12):1602-1611. doi:10.1373/clinchem.2016.257485 
68. Aakre KM, Roraas T, Petersen PH, et al. Weekly and 90-minute biological variations in cardiac troponin $\mathrm{T}$ and cardiac troponin I in hemodialysis patients and healthy controls. Clin Chem. 2014;60(6):838-847. doi:10.1373/clinchem.2013.216978

69. Chaulin AM, Duplyakov DV. High-sensitivity cardiac troponins: circadian rhythms. Cardiovasc Ther Prev. 2021;20(1):2639. In Russian. doi:10.15829/1728-8800-2021-2639

70. van der Linden N, Cornelis T, Klinkenberg LJJ, et al. Strong diurnal rhythm of troponin $\mathrm{T}$, but not troponin $\mathrm{I}$, in a patient with renal dysfunction. Int $J$ Cardiol. 2016;221:287-288. doi:10.1016/j.ijcard.2016.06.268

71. Roffi M, Patrono C, Collet J, et al. 2015 ESC Guidelines for the management of acute coronary syndromes in patients presenting without persistent ST-segment elevation: task force for the management of acute coronary syndromes in patients presenting without persistent ST-segment elevation of the European Society of Cardiology (ESC). Eur Heart J. 2016;37:267-315. doi:10.1093/ eurheartj/ehv320

72. Seneviratna A, Lim GH, Devi A, et al. Circadian dependence of infarct size and acute heart failure in ST elevation myocardial infarction. PLoS One. 2015;10(6):e0128526. doi:10.1371/journal. pone. 0128526

73. Suárez-Barrientos A, López-Romero P, Vivas D, et al. Circadian variations of infarct size in acute myocardial infarction. Heart. 2011;97:970-976. doi:10.1136/hrt.2010.212621

74. Ziebig R, Lun A, Hocher B, et al. Renal elimination of troponin T and troponin I. Clin Chem. 2003;49(7):1191-1193. doi:10.1373/ 49.7.1191

75. Ellis K, Dreisbach AW, Lertora J. Plasma elimination of cardiac troponin I in end-stage renal disease. South Med J. 2001;94 (10):993-996. doi:10.1097/00007611-200194100-00011

76. Pervan $P$, Svaguša $T$, Prkačin $I$, et al. Urine high sensitive Troponin I measuring in patients with hypertension. Signa Vitae. 2017;13(Suppl3):62-64. doi:10.22514/SV133.062017.13

77. Chaulin AM, Duplyakova PD, Bikbaeva GR, et al. Concentration of high-sensitivity cardiac troponin I in the oral fluid in patients with acute myocardial infarction: a pilot study. Russ J Cardiol. 2020;25(12):3814. doi:10.15829/1560-4071-2020-3814

78. Mirzaii-Dizgah I, Riahi E. Salivary high-sensitivity cardiac troponin $\mathrm{T}$ levels in patients with acute myocardial infarction. Oral Dis. 2013;19(2):180-184. doi:10.1111/j.1601-0825.2012.01968.x

79. Chaulin AM, Duplyakov DV. Increased natriuretic peptides not associated with heart failure. Russ J Cardiol. 2020;25:4140. doi:10.15829/1560-4071-2020-4140

80. Potkonjak AM, Sabolović Rudman S, Nikolac Gabaj N, et al. Urinary troponin concentration as a marker of cardiac damage in pregnancies complicated with preeclampsia. Med Hypotheses. 2020;144:110252. doi:10.1016/j.mehy.2020.110252

81. Nowakowski JF. Use of cardiac enzymes in the evaluation of acute chest pain. Ann Emerg Med. 1986;15(3):354-360. doi:10.1016/s0196-0644(86)80584-4

82. Alpert JS, Thygesen K, Antman E, et al. Myocardial infarction redefined-a consensus document of The Joint European Society of Cardiology/American College of Cardiology Committee for the redefinition of myocardial infarction [published correction appears in J Am Coll Cardiol 2001;37(3):973]. J Am Coll Cardiol. 2000;36(3):959-969. doi:10.1016/s0735-1097(00) 00804-4

83. Cummins B, Auckland ML, Cummins P. Cardiac-specific troponin-I radioimmunoassay in the diagnosis of acute myocardial infarction. Am Heart J. 1987;113(6):1333-1344. doi:10.1016/ 0002-8703(87)90645-4

84. Venge P, Lindahl B. Cardiac troponin assay classification by both clinical and analytical performance characteristics: a study on outcome prediction. Clin Chem. 2013;59:976-981. doi:10.1373/ clinchem.2012.194928
85. Katus HA, Looser S, Hallermayer K, et al. Development and in vitro characterization of a new immunoassay of cardiac troponin T. Clin Chem. 1992;38(3):386-393. doi:10.1093/clinchem/38.3.386

86. Hermsen D, Apple F, Garcia-Beltràn L, et al. Results from a multicenter evaluation of the 4th generation Elecsys Troponin T assay. Clin Lab. 2007;53(1-2):1-9.

87. Reichlin T, Hochholzer W, Stelzig C, et al. Incremental value of copeptin for rapid rule out of acute myocardial infarction. $J$ Am Coll Cardiol. 2009;54(1):60-68. doi:10.1016/j.jacc.2009.01.076

88. Mingels A, Jacobs L, Michielsen E, et al. Reference population and marathon runner sera assessed by highly sensitive cardiac troponin $\mathrm{T}$ and commercial cardiac troponin T and I assays. Clin Chem. 2009;55(1):101-108. doi:10.1373/clinchem.2008.106427

89. Keller T, Zeller T, Ojeda F, et al. Serial changes in highly sensitive troponin I assay and early diagnosis of myocardial infarction. JAMA. 2011;306(24):2684-2693. doi:10.1001/jama.2011.1896

90. Adams JE, Bodor GS, Dávila-Román VG, et al. Cardiac troponin I. A marker with high specificity for cardiac injury. Circulation. 1993;88(1):101-106. doi:10.1161/01.cir.88.1.101

91. Apple FS. Counterpoint: standardization of cardiac troponin I assays will not occur in my lifetime. Clin Chem. 2012;58 (1):169-171. doi:10.1373/clinchem.2011.166165

92. Boeddinghaus J, Nestelberger T, Koechlin L, et al.; APACE Investigators. Early diagnosis of myocardial infarction with point-of-care high-sensitivity cardiac troponin I. $\mathrm{J} \mathrm{Am} \mathrm{Coll}$ Cardiol. 2020;75(10):1111-1124. doi:10.1016/j.jacc.2019.12.065

93. Anand A, Shah ASV, Beshiri A, et al. Global adoption of high-sensitivity cardiac troponins and the universal definition of myocardial infarction. Clin Chem. 2019;65(3):484-489. doi:10.1373/clinchem.2018.298059

94. Zahran S, Figueiredo VP, Graham MM, Schulz R, Hwang PM. Proteolytic digestion of serum cardiac troponin I as marker of ischemic severity. JALM. 2018;3:450-455. doi:10.1373/ jalm.2017.025254

95. Katrukha IA, Kogan AE, Vylegzhanina AV, et al. Full-size cardiac troponin I and its proteolytic fragments in blood of patients with acute myocardial infarction: antibody selection for assay development. Clin Chem. 2018;64(7):1104-1112. doi:10.1373/ clinchem.2017.286211

96. Katrukha IA, Kogan AE, Vylegzhanina AV, et al. Thrombinmediated degradation of human cardiac troponin T. Clin Chem. 2017;63(6):1094-1100. doi:10.1373/clinchem.2016.266635

97. Chaulin AM, Karslyan LS, Nurbaltaeva DA, et al. Cardial troponins metabolism under normal and pathological conditions. Siber Med Rev. 2019;(6):5-14. doi:10.20333/2500136-2019-6-5-14

98. Lippi G, Aloe R, Meschi T, et al. Interference from heterophilic antibodies in troponin testing. Case report and systematic review of the literature. Clin Chim Acta. 2013;426:79-84. doi:10.1016/j. cca.2013.09.004

99. Adamczyk M, Brashear RJ, Mattingly PG. Circulating cardiac troponin-I autoantibodies in human plasma and serum. Ann $N \quad Y \quad$ Acad Sci. 2009;1173(1):67-74. doi:10.1111/j.17496632.2009.04617.x

100. Tang G, Wu Y, Zhao W, Shen Q. Multiple immunoassay systems are negatively interfered by circulating cardiac troponin I autoantibodies. Clin Exp Med. 2012;12(1):47-53. doi:10.1007/ s10238-011-0141-X

101. Armbruster DA, Pry T. Limit of blank, limit of detection and limit of quantitation. Clin Biochem Rev. 2008;29(Suppl1):S49-S52.

102. Apple FS. A new season for cardiac troponin assays: it's time to keep a scorecard. Clin Chem. 2009;55:1303-1306. doi:10.1373/ clinchem.2009.128363

103. Collinson PO, Heung YM, Gaze D, et al. Influence of population selection on the 99th percentile reference value for cardiac troponin assays. Clin Chem. 2012;58(1):219-225. doi:10.1373/ clinchem.2011.171082 
104. Eggers KM, Apple FS, Lind L, et al. The applied statistical approach highly influences the 99th percentile of cardiac troponin I. Clin Biochem. 2016;49(15):1109-1112. doi:10.1016/j. clinbiochem.2016.08.012

105. Cervellin G, Mattiuzzi C, Bovo C, et al. Diagnostic algorithms for acute coronary syndrome-is one better than another? Ann Transl Med. 2016;4(10):193. doi:10.21037/atm.2016.05.16

106. Sörensen NA, Neumann JT, Ojeda F, et al. Challenging the 99th percentile: a lower troponin cutoff leads to low mortality of chest pain patients. Int $J$ Cardiol. 2017;232:289-293. doi:10.1016/j. ijcard.2016.12.167

107. Lippi G, Bonfanti L, Dipalo M, et al. Clinical, organizational and economic analysis of high-sensitivity cardiac troponin testing in the emergency department. Ann Res Hosp. 2017;1:44. doi:10.21037/arh.2017.09.02

108. Pickering JW, Than MP, Cullen L, et al. Rapid rule-out of acute myocardial infarction with a single high-sensitivity cardiac troponin $\mathrm{T}$ measurement below the limit of detection: a collaborative meta-analysis [published correction appears in Ann Intern Med. 2017 Oct 3;167(7):528]. Ann Intern Med. 2017;166(10):715-724. doi:10.7326/M16-2562

109. Ferencik M, Mayrhofer T, Lu MT, et al. High-sensitivity cardiac troponin I as a gatekeeper for coronary computed tomography angiography and stress testing in patients with acute chest pain. Clin Chem. 2017;63:1724-1733. doi:10.1373/clinchem.2017.275552

110. Jaeger C, Wildi K, Twerenbold R, et al. One-hour rule-in and rule-out of acute myocardial infarction using high-sensitivity cardiac troponin I. Am Heart J. 2016;171(1):92-102.e1025. doi:10.1016/j.ahj.2015.07.022

111. Available from: https://www.ifcc.org/media/478231/highsensitivity-cardiac-troponin-i-and-t-assay-analyticalcharacteristics-designated-by-manufacturer-v122019.pdf. Accessed March 25, 2020.

112. Reichlin T, Schindler C, Drexler B, et al. One-hour rule-out and rule-in of acute myocardial infarction using high-sensitivity cardiac troponin T. Arch Intern Med. 2012;172(16):1211-1218. doi:10.1001/archinternmed.2012.3698

113. Twerenbold R, Neumann JT, Sörensen NA, et al. Prospective Validation of the 0/1-h Algorithm for Early Diagnosis of Myocardial Infarction. J Am Coll Cardiol. 2018;72(6):620-632. doi:10.1016/j.jacc.2018.05.040

114. Twerenbold R, Costabel JP, Nestelberger T, et al. Outcome of applying the ESC 0/1-hour algorithm in patients with suspected myocardial infarction. J Am Coll Cardiol. 2019;74(4):483-494. doi:10.1016/j.jacc.2019.05.046

115. Shah ASV, Anand A, Strachan FE, et al. High-sensitivity troponin in the evaluation of patients with suspected acute coronary syndrome: a stepped-wedge, cluster-randomised controlled trial. Lancet. 2018;392(10151):919-928. doi:10.1016/S0140-6736(18) 31923-8
116. Shah AS, Anand A, Sandoval Y, et al. High-sensitivity cardiac troponin I at presentation in patients with suspected acute coronary syndrome: a cohort study. Lancet. 2015;386 (10012):2481-2488. doi:10.1016/S0140-6736(15)00391-8

117. Boeddinghaus J, Reichlin T, Cullen L, et al. Two-hour algorithm for triage toward rule-out and rule-in of acute myocardial infarction by use of high-sensitivity cardiac troponin I. Clin Chem. 2016;62(3):494-504. doi:10.1373/clinchem.2015.249508

118. Nestelberger T, Wildi K, Boeddinghaus J, et al. Characterization of the observe zone of the ESC 2015 high-sensitivity cardiac troponin $0 \mathrm{~h} / \mathrm{h}$-algorithm for the early diagnosis of acute myocardial infarction. Int J Cardiol. 2016;207:238-245. doi:10.1016/ j.ijcard.2016.01.112

119. Greenslade JH, Carlton EW, Van Hise C, et al. Diagnostic accuracy of a new high-sensitivity troponin i assay and five accelerated diagnostic pathways for ruling out acute myocardial infarction and acute coronary syndrome. Ann Emerg Med. 2018;71(4):439-451.e3. doi:10.1016/j.annemergmed.2017.10.030

120. Greenslade J, Cho E, Van Hise C, et al. Evaluating rapid rule-out of acute myocardial infarction using a high-sensitivity cardiac troponin I assay at presentation. Clin Chem. 2018;64 (5):820-829. doi:10.1373/clinchem.2017.283887

121. Nestelberger T, Boeddinghaus J, Greenslade J, et al. Two-hour algorithm for rapid triage of suspected acute myocardial infarction using a high-sensitivity cardiac troponin I assay. Clin Chem. 2019;65(11):1437-1447. doi:10.1373/clinchem.2019.305193

122. Clerico A, Padoan A, Zaninotto M, et al. Clinical relevance of biological variation of cardiac troponins. Clin Chem Lab Med. 2020. doi:10.1515/cclm-2020-1433

123. Sigurdardottir FD, Lyngbakken MN, Holmen OL, et al. Relative prognostic value of cardiac troponin I and c-reactive protein in the general population (from the nord-trøndelag health [HUNT] study). Am J Cardiol. 2018;121:949-955. doi:10.1016/j. amjcard.2018.01.004

124. Pettit MA, Koyfman A, Foran M. Myocarditis. Pediatr Emerg Care. 2014;30(11):832-5;quiz 836-8. doi:10.1097/ PEC.0000000000000272

125. Chaudary N, Geraci SA. Prognostic value of cardiac-specific troponins in chronic obstructive pulmonary disease exacerbations: a systematic review. J Miss State Med Assoc. 2014;55(2):40-44.

126. Gaze DC. Clinical utility of cardiac troponin measurement in COVID-19 infection. Ann Clin Biochem. 2020;57(3):202-205. doi:10.1177/0004563220921888
Vascular Health and Risk Management

\section{Publish your work in this journal}

Vascular Health and Risk Management is an international, peerreviewed journal of therapeutics and risk management, focusing on concise rapid reporting of clinical studies on the processes involved in the maintenance of vascular health; the monitoring, prevention and treatment of vascular disease and its sequelae; and the involvement of metabolic disorders, particularly diabetes. This journal is indexed on PubMed Central and MedLine. The manuscript management system is completely online and includes a very quick and fair peerreview system, which is all easy to use. Visit http://www.dovepress. com/testimonials.php to read real quotes from published authors. 